\title{
АНАЛИЗ ПРОФЕССИОНАЛЬНО ЗНАЧИМЫХ КАЧЕСТВ ПРОФЕССИОГРАММЫ СОВРЕМЕННОГО ЭКОНОМИСТА
}

\section{ANALYSIS OF PROFESSIONALLY SIGNIFICANT QUALITIES AND JOB DESCRIPTION OF THE MODERN ECONOMIST}

\section{N. Koshevaya}

Summary: The professionally significant qualities of a modern economist constitute one of the important characteristics of his professiogram. For the formation of these qualities, it is necessary to know the requirements that the profession of an economist imposes on the individual. Based on the specific features of economic activity, in this article, using the method of theoretical analysis, we have analyzed some of the essential professionally significant qualities of a modern economist, which, we believe, contribute to the effective implementation of his professional activity.

Keywords: professiogram, professionally significant qualities of an economist, good memory of an economist, analytical thinking, mathematical thinking, intuition, creativity, business acumen, selfimprovement, modernity.
Кошевая Наталья Сергеевна

старший преподаватель, Российский университет дружбы народов natysik-1969@mail.ru

Аннотация: Профессионально значимые качества современного экономиста составляют одну из немаловажных характеристик его профессиограммы. Для формирования данных качеств необходимо знать те требования, которые предъявляет профессия экономиста к личности. Исходя из специфических особенностей экономической деятельности, нами в данной статье методом теоретического анализа проанализированы одни из существенных профессионально значимых качеств современного экономиста, которые, как мы полагаем, способствуют эффективной реализации его профессиональной деятельности.

Ключевые слова: профессиограмма, профессионально значимые качества экономиста, хорошая память экономиста, аналитическое мышление, математическое мышление, интуиция, креативность, деловая хватка, самосовершенствование, современность.
A нализ профессиональной деятельности современного экономиста способного конкурировать на рынке труда показал, что они должны обладать: стремлением к совершенствованию своих профессиональных способностей, уметь оценивать социально-экономические процессы, анализировать, прогнозировать результаты собственных решений и брать за них ответственность, быть коммуникабельными и творческими личностями.

Как видим, перечисленные характеристики в аддитивности своей представляют базовую основу профессионально значимых качеств экономиста, которые в свою очередь составляют один из аспектов его профессиограммы.

Поэтому основной целью данной статьи является анализ профессионально значимых личных качеств будущего экономиста, составляющие одну из базисных платформ его профессиографической структуры.

Профессиограмма - это документ, который описывает содержание работы по определенной профессии (функции, обязанности, операционные задачи и т.д.) и определяет требования к представителям данной профессии (личные, профессиональные и деловые качества).
Анализ образовательного стандарта направления «Экономика», профессионального стандарта экономических специальностей показал, что в профессиографическую структуру бакалавра экономического направления можно включить следующие качества:

- хорошая память, посредством которой экономист способен обработать большой объем экономических показателей. Хорошая память экономиста — это один из самых востребованных психических процессов профессионала экономики, благодаря которому он может запоминать, сохранять и воспроизводить в нужный момент необходимую информацию. Благодаря хорошей памяти экономист способен воспроизводить не только отдельные экономические явления и процессы, но и целую последовательность связанных между собой событий.

Эффективность профессиональной деятельности экономиста зависит от того, насколько развиты его ведущие виды памяти. К одним из таки видов мы относим оперативную и долговременную память.

Оперативная память функционирует в рамках фиксированного времени, а долговременная память сохраняет информацию на долгий срок. Посредством данных видов памяти экономист способен решать как сиюминутные, так и прогностические профессиональные задачи. 
Следующий вид памяти, который также определяет, по нашему мнению, эффективность профессиональной деятельности экономиста - это зрительная память. Зрительная память способствует сохранению и воспроизведению зрительных образов, к которым относятся большие массивы текстовых, числовых и графических показателей.

Немаловажная роль в профессиональной деятельности экономиста отводится словесно-логической памяти, на основе которой экономист способен запоминать экономические явления, процессы, а посредством суждений осуществлять необходимые умозаключения. Данный вид памяти является уникальным, поскольку мысли не существуют без языка, поэтому точную, объемную экономическую информацию не нужно запоминать, достаточно запомнить ее смысл, поскольку запомненная суть информации легко воспроизводится своими словами.

Таким образом, рассмотренная классификация видов памяти в своей взаимообусловленной связи определяют фундамент хорошей памяти экономиста, что способствует выполнению его качественной профессиональной деятельности.

Аналитическое и математическое мышление - способность проанализировать и произвести расчетную деятельность в соответствии с поставленной задачей.

Аналитическое мышление - это одно из редких качеств экономиста, на базе которого он способен к анализу и логике необходимой информации, поскольку аналитическое мышление включает в себя:

- анализ экономических фактов, явлений и процессов;

- построение логических цепочек;

- способность к абстрагированию;

- прогнозирование;

- четкое изложение мыслей;

- последовательность умозаключения.

Экономисты, владеющие аналитическим мышлением способны видеть выход в самых сложных профессиональных ситуациях, строить логические причинно-следственные связи в экономике и обрабатывать большое количество информации, которая систематически обновляется.

Аналитическое мышление тесно взаимосвязано с математическим мышлением и опирается на его математический инструментарий. Такая связь помогает экономисту методами математического моделирования не только устанавливать экономические закономерности, но и рассчитывать на основе предполагаемых связей между объектами и процессами их дальнейшее разви- тие и с помощью математических методов обосновывать выводы.

Математическое мышление экономиста - это абстрактное мышление, в котором все рассматриваемые объекты должны быть связаны каким-либо отношением. Специалист экономики, у которого развито математическое мышление, понимает, что у любой профессиональной задачи есть решение и в процессе этого решения он должен уметь разложить цепочку поиска проблем на последовательные этапы.

Анализ типов математического мышления показал, что эффективность экономической деятельности будет зависеть от таких типов математического мышления как топологическое, порядковое, метрическое и проективное, поскольку при топологическом мышлении экономист способен определить траекторию действий, изучить проблему, а затем не спеша и тщательно довести решение профессиональной задачи до конца. На основе порядкового мышления придерживается строгий линейный порядок профессиональной деятельности, который осуществляется от начального к конечному этапу. При решении профессиональных задач основное значение придается параметрам объектов изучения и их соотношению, деятельность осуществляется по четко разработанному плану и по конкретному алгоритму. Посредством метрического мышления экономическая деятельность сводится к рассмотрению конкретных величин. Экономисты с данным типом мышления руководствуются точными параметрами, точно знают, какие конкретные результаты должны, получится в ходе решение профессиональных задач, и какими путями этого можно добиться. Проективное мышление экономиста позволяет же рассматривать экономические явления и процессы с различных сторон, определять множества вариантов действий в нестандартных решениях.

Таким образом, аналитическое и математическое мышление экономиста - это высокоорганизованное мышление, которое в современном мире является важным параметром для осуществления деятельности на высоком профессиональном уровне.

Высокая концентрация внимания - способность выявлять из обширной экономической информации необходимую и важную.

Концентрация - это способность экономиста сфокусировать свое внимание на конкретной задаче в течение некоторого времени. Профессиональная деятельность экономиста связана с необходимостью обрабатывать большие объемы информации и выполнять монотонные и однообразные задачи в течение долгого времени, поэтому эффективность его профессиональной деятельности зависит от того насколько он способен поддержи- 
вать высокую концентрацию внимания в течение этого времени. Поэтому экономист, владеющий высокой концентрацией внимания, способен:

- быстрее вникнуть в суть профессиональной задачи;

- идти к поставленной цели не отвлекаясь на второстепенные вопросы;

- решать лишь одну из поставленных задач, что приводит к конечному ее решению;

- сознательно направлять свои мысли на конкретную задачу.

Таким образом, умение современного экономиста к концентрации является необходимым навыком в решении глобальных экономических задач.

Интуичия - способность к точности прогнозирования и проектирования с разумным риском.

Интуиция экономиста - мыслительный процесс, на основе которого осуществляется быстрое решение профессиональных задач при недостаточной осознанности логических связей экономических явления и процессов.

Интуиция имеет немаловажное значение для экономической деятельности, поскольку способствует открытию и использованию новых знаний для преобразования или совершенствования экономических реалий, а также экономит время в процессе исследований, порождает смелые гипотезы, которые логически доказываются в ходе экспериментов.

В основе механизмов интуиции находятся различные виды сложной переработки информации, поэтому в интуиции важную роль играют обобщения, в этом случае на основе необходимой информации, экономист способен выдать решение проблемы быстрее, чем прийти к ней логически. В этом случае экономист должен обладать всесторонней ориентацией в экономической сфере деятельности, обладать соответствующей компетентностью в области решения конкретных профессиональных задач, а также иметь определенный опыт.

Обзор научных работ показал, что существует несколько видов интуиций, но для эффективной профессиональной деятельности, по нашему мнению, необходимо современному экономисту владеть обычной, экспертной и стратегической интуицией, определенных профессором бизнес-школы Колумбийского университета Уильямом Дагганом.

На основе обычной интуиции экономист способен делать правильный выбор в повседневном решении экономических задач и составлять мнение о не знакомых ему ситуациях и проблемах.
Посредством экспертной интуиции экономист принимает мгновенные решения в знакомых ему ситуациях, поскольку на подсознательном уровне выдает решение на базе накопленного опыта.

Самая сложная и длительная интуиция - это стратегическая интуиция, на основе которой реализуются прогностические и проектные ситуации. Особенностью данной интуиции является то, что результат может прийти в самый неожиданный момент. Поэтому данный вид интуиции применяется только в тех случаях, когда на ситуацию экономист способен посмотреть с позиции своего опыта и профессиональных знаний, оценивая происходящее и, предполагая последствия прогнозирования и проектирования.

Таким образом, эффективность экономической деятельности, по нашему мнению, обуславливается владение в равнозначной степени всеми видами интуиции предложенными У. Дагганом.

Креативность - способность к созданию новых, нестандартных идей в процессе профессиональной деятельности.

Для понимания сущности креативности экономиста необходимо рассмотреть сам феномен «креативность». Анализ научной литературы показал, что однозначной терминологии не существует, поскольку креативность проявляется как в бытовой, так и в профессиональной сфере деятельности человека.

Анализ зарубежной литературы показал, что зарубежные ученые представляют креативность как:

- черту личности (А.Х. Маслоу, К. Роджерс и др.);

- способность личности (К. Смит, Э. Фромм и др.);

- продукт (Дж. П. Гилфорд, Г. Уоллес, С. Медник, 3. Фрейд и др.);

- процесс (П. Торренс, Д. Симсон, и др.).

Согласно американскому психологу А.Х. Маслоу креативность - это творческая врожденная черта личности, которая теряется, по мнению автора, в процессе воздействия на личность различных факторов (обучения, воспитания и социальной политики) [2].

Э. Фромм понимает под креативностью способность удивлять и находить нестандартные решения в различных ситуациях. По мнению автора, «...это нацеленность на открытие нового и способность к глубокому осознанию своего опыта» [6].

П. Торренс рассматривает креативность как процесс, состоящий из фаз (фиксация проблем, поиск их решения, выдвижение гипотез и формулировка результатов решения), приводящих человека в определенное пси- 
хологическое состояние (напряжение, разочарование, радость и концентрация) [3].

По мнению же отечественных ученых, таких как Ю.И. Салов и Ю.С. Тюнников креативность - это «творческие способности, которые могут проявляться в мышлении, чувствах, общении, отдельных видах деятельности, характеризовать личность в целом и ее отдельные стороны, продукты деятельности и процесс их созидания» [4].

М.А. Холодная креативность описывает как способность к порождению множества идей в нерегламентированных условиях деятельности [5].

Таким образом, анализируя понятие «креативность», мы пришли к выводу, что креативность современного экономиста - это его способность искать уникальные решения профессиональных задачи и находить неординарные выходы из различных экономических ситуаций.

Преимущества будущего экономиста с креативным мышлением состоит в том, что оно помогает ему:

- решать проблемы совершенно новыми нетрадиционными способами;

- отказываться от стереотипного мышления;

- проявлять гибкость и оригинальность в принятии решений;

- быть предрасположенным к анализу и синтезу;

- интуитивно чувствовать правильное направление мысли;

— генерировать большое количество идей.

Исходя из вышеперечисленных преимуществ креативного мышления современного экономиста, определим его критерии.

К одним из таких критериев креативного мышления современного экономиста мы относим беглость и гибкость. Беглость проявляется в количестве идей, возникших за единицу времени в процессе решения проблем на основе гибкого принятия решений.

Следующая пара критериев - это оригинальность и восприимчивость, позволяющие экономисту производить необычные идеи при решении профессиональных задач, быть чувствительным к необычным деталям и быстро переключаться с одной идеи на другую.

Также немаловажным критерием креативности является метафоричность. На основе метафоричности проявляется исключительная способность экономиста работать в совершенно необычном контексте и иметь ассоциативное мышление.

Сообразительность - способность к поиску быстрых, редких и неочевидных решений профессиональ- ных задач.

Сообразительность современного экономиста - это его способность искать необычные и интересные пути решения профессиональных задач, не следуя привычным для всех правилам.

Поскольку сообразительность это не только способность работать с образами, но и, в отличие от логического мышления, иметь особый навык видения проблем, то современный экономист владеющий сообразительностью имеет ряд преимуществ, таких как:

- умеет кратчайшим путем достичь результата в решении профессиональной проблемы;

- найди лучшее решение проблемы;

- внимательны к тому, что происходит вокруг проблемы;

- особое внимание к самым мелким деталям проблем.

Особенностью сообразительного экономиста является умение по изученным деталям увидеть проблему в целом и по общему образу найти пути ее решения.

Деловая хватка - способность к безупречному планированию и организации работы, умение сочетаться с моментальным переходом к профессиональным действиям для достижения высоких и выгодных результатов.

Деловая хватка экономиста - это свойство профессионала, заключающееся в его мобильности, предприимчивости и инициативе. Это его особое качество, которое позволяет экономисту обнаружить возможность в профессиональной деятельности (в аргументированных переговорах, в перестройке профессиональной деятельности, самосовершенствовании и др.) и эту возможность не упустить.

Деловая хватка - это искусство, на основе которого соединены навыки экономиста в точной и емкой оценке экономических тенденций с четким пониманием того, как можно решить профессиональные задачи, - и только потом реализовывать стратегию для достижения желаемого результата.

Деловая хватка подразумевает интенсивную умственную деятельность. Наблюдение за внешней средой организации требует хорошо развитых логических навыков и умения составлять общую картину, оценивать, отбрасывать или принимать большое количество предположений в короткий промежуток времени. Поскольку экономическая ситуация непрерывно меняется, эта задача становится трудна вдвойне - экономист постоянно вынуждены пересматривать свои выводы и решения. 
Слово «хватка» тесно связано с понятием «интуиция экономиста», способного к остроте и глубине восприятия практических дел.

Коммуникабельность - способность экономиста общаться с оппонентами на любом уровне, уметь вести деловые переговоры и договариваться о выгодных условиях сделки.

Ценность такого сотрудника заключается в том, что именно такого человека отправляют на переговоры. Особенностью коммуникабельности являются интересное общение, жестикуляция, умение подобрать интонацию в разговоре, поставленная, яркая и живая речь.

Коммуникабельный экономист - это образованный и тактичный человек, который не просто ведет беседу, а преследует определенную цель: успокоить недовольного клиента, склонить партнера к сделке, сократить сроки и т.д. Он знает как вест переговоры, и добиться результатов.

Коммуникабельным экономистам характерна гибкость в контактах, способность и умение не растеряться в общении при любых ситуациях, уверенность в себе, они легко приспосабливаются к новым условиям, умеют успешно проводить переговоры, стремятся к инициативности.

Таким образом, к основным достоинствам коммуникабельного экономиста относятся: умение общаться, спокойствие и внимательность.

В понятие «умение общаться», мы вкладываем способность экономиста к выслушиванию и поддержанию разговора, где он может найти точки соприкосновения и развить общие интересы, другими словами, расположить собеседника к себе, чтобы затем склонить его на свою сторону.

Спокойствие же коммуникабельного профессионала притягивает любого собеседника, поскольку от него не исходит тревога, суетливость и боязнь участвовать в переговорах.

Доброжелательность и открытость, исходящая от коммуникабельного экономиста, обуславливает в большей степени удачный исход в решение профессиональных задач.

Внимательность коммуникабельного собеседника выражается в том, что он первый реагирует на приветствия, сглаживает конфликты и подводит итоги переговоров. С ними не возникает неловких пауз и бессмысленных разговоров. После встречи с ними остается позитивный настрой о проделанной работе.
Самосовершенствование - способность к целенаправленному развитию деловых способностей и умений для достижения гармонии в профессиональной деятельности, следовательно, самосовершенствоваться профессионально.

Профессиональное самосовершенствование - это работа на собой, осознанное стремление улучшить свои профессиональные качества, навыки и умения необходимые для профессии.

Одним из важнейших аспектов самосовершенствования является профессиональное самопознание это процесс познания самого себя в профессии, своих потенциальных и актуальных способностей и возможностей, интеллектуальных способностей, черт своего характера и своего умения общения с другими людьми. Самопознание в профессии невозможно без осознания и оценки своей деятельности.

Профессиональное самосовершенствование - это обязательная составляющая в выработке необходимых таких качеств экономиста, как целеустремленность и уверенность в себе, что в конечном итоге позволит стать успешным профессионалом своего дела. К отличительным характеристикам успешного экономиста мы относим такие характеристики, как:

- уверенность в себе;

- трезвый взгляд на любую экономическую ситуацию;

- способность нести ответственность за принятия решений и полагаться на себя в любой кризисной ситуации;

- уметь побороть сомнения и страх;

- энергия и самоконтроль, цельность и уравновешенность в профессиональной деятельности;

- любознательность и всестороннее развитие личности, позволяющей замечать все нюансы, остро чувствовать новизну, новые тенденции с позитивным мышлением.

Таким образом, самосовершенствование экономиста обуславливает траекторию приобретения новых профессиональных умений и навыков, способствует становлению личности более интересной и профессиональной.

Самокритичность - способность к объективной оценке собственных профессиональных действий в различных условиях и обстоятельствах.

Самокритичность экономиста определяется его рефлексивным отношением к себе как профессионалу, способностью к поиску решений своих профессиональных ошибок, оценке своей профессиональной деятельности и к анализу результатов своего мышления. 
Анализ себя в профессиональной деятельности на основе самокритичности является объективным и реалистичным, поскольку дает реальную оценку собственных достоинств и недостатков.

Поэтому основными критериями самокритичности современного экономиста являются:

- умение отстраненно взглянуть на себя в трудовой деятельности, увидеть собственные ошибки и по возможности их устранить;

- умение отнестись к своим действиям без предубежденности в своей правоте;

- умение трезво оценить свои действия в любых профессиональных ситуациях, сочетание ума, позволяющего увидеть промахи, и смелости, позволяющей их признать;

- отсутствия самолюбования и желания собственного личного роста.

Таким образом, экономист, владеющий самокритичностью, готов к самосовершенствованию, обладает способностью признавать свои профессиональные ошибки и дает объективную оценку собственному профессионализму, а также освобождается от неуважительного отношения к окружающим.

Современность - владение современными техноло- гиями по сбору, обработке, анализу экономических показателей.

Требования к современности в экономической деятельности составляют сложный комплекс, свидетельствующий об особых трудностях и многообразии профессиональной деятельности экономиста, поскольку она сопряжена с постоянным колебанием социальноэкономической политики в стране.

Одной из главных свойств современности экономиста является систематическое развитие инновационных экономических умений и навыков, широкой эрудиции, высокой экономической культуры и наличие хорошо развитых коммуникабельных способностей.

Большое значение в современности имеет умение эффективно применить полученный арсенал знаний в профессиональной деятельности для ускорения экономического развития страны.

\section{ВывоА}

Таким образом, рассмотренная нами совокупность профессионально значимых качеств экономиста определяет, по нашему мнению, его характеристику, на основе которой он способен осуществлять профессиональную деятельность в современных условиях.

\section{ЛИТЕРАТУРА}

1. Маслоу, А.Г. Мотивация и личность / Перевод. с англ. Татлыбаевой А.М. СПб.: Евразия, 1999.— 411 с.— Текст : непосредственный.

2. Torrance E.P. Guiding creative talent — Englewood Cliffs. NY: Prentice-Hall, 1964.

3. Салов, Ю.И., Тюнников, Ю.С. Психолого-педагогическая антропология: Учебное пособие для студентов высших учебных заведений / Ю.И. Салов, ТюнниКОВ, Ю.С. - М : - Из-Во ВЛАДОС-ПРЕСС, 2003. — 256 с.- Текст : непосредственный.

4. Холодная, М.А. Психология развития творческого потенциала личности / М.А. Холодова.— М. : «Флинта», 1997.—224 с.— Текст: непосредственный.

5. Фромм, Э. Иметь или быть / Э. Фромм. — Из-во АСТ, АСТ Москва,—2007.—320 c.— Текст : непосредственный.

(с) Кошевая Наталья Сергеевна (natysik-1969@mail.ru).

Журнал «Современная наука: актуальные проблемы теории и практики» 